\title{
Membrane Potentials of Nickel Hydroxide Precipitate Membranes
}

\author{
M. Sakashita and N. Sato \\ Electrochemistry Laboratory, Faculty of Engineering, \\ Hokkaido University*
}

\begin{abstract}
Measurements of membrane potentials across nickel hydroxide precipitate membranes have been made to estimate the transport number of anions, the order of selectivity for anions, and the fixed charge concentration. The membranes show a high selectivity for anions; from the measurements of the membrane potentials, the transport number for anions evaluated to be 0.98 in sodium chloride, nitrate, perchlorate, and sulphate solutions. The order of the selectivity for anions determined with the biionic potentials is $\mathrm{OH}^{-}>\mathrm{SO}_{4}{ }^{2-}>\mathrm{Br}^{-}>\mathrm{I}^{-}>\mathrm{Cl}^{-}>\mathrm{NO}_{3}{ }^{-}>\mathrm{ClO}_{4}{ }^{-}$. This order of the selectivity is the same as that of the mobility in aqueous solutions, but the difference in the selectivity for these anions is greater in the membranes than in aqueous solutions. Nickel cations on nickel hydroxide precipitates constitute the fixed ion matrix characterizing the membranes as an anion exchanger, and its concentration is determined to be about $0.4 \mathrm{~g}$ equiv./liter by comparing the experimental membrane potentials with the theoretical values according to the fixed charge theory of membranes.
\end{abstract}

\section{Introduction}

In colloid chemistry, it is well known that precipitates of hydrous metal oxides or hydroxides exhibit some selectivity for adsorption of ionic species. $^{1-5)}$ When metals corrode in aqueous solution, hydrous metal oxide precipitates formed as corrosion products often cover the surface of corroding metals. Under such circumstances, the precipitate products act as an electrolyte in contact to the metal, and corrosion behavior of the metal is affected by the perm-selective property of the surface precipitate layers for ionic species in the solution. The evaluation of the perm-selective property of corrosion product layers can be made by using precipitate membranes produced artificially. Along this line Ruetschi ${ }^{6}$ ) studied the corrosion of $\mathrm{Pb}$ in aqueous $\mathrm{H}_{2} \mathrm{SO}_{4}$ solution and showed that the behavior of $\mathrm{PbSO}_{4}$ layer on $\mathrm{Pb}$ was similar to that of perm-selective $\mathrm{PbSO}_{4}$ precipitate membranes.

A few papers ${ }^{7,8)}$ have been reported on hydrous iron oxide membranes produced artificially in relation to the corrosion of iron and steels, in which the membranes were shown to be anion-selective. Nickel hydroxide precipitate membranes have also been found to be anion-selective, and the ion transport properties through the membranes have been studied in previous paper. ${ }^{9)}$ In this work, measurements of the membrane potentials have

* Kita 13-jo, Nishi 8-chome, Kita-ku, Sapporo 060, Japan been carried out for several nickel hydroxide membranes to evaluate the perm-selectivity for anions, the order of selective transport among anion species, and the concentration of fixed ion on the membranes.

The membrane potential is the potential difference across an ion exchange membrane which separates two solutions of the same electrolyte with different concentrations. According to Scatchard ${ }^{101}$, it is expressed by,

$$
\Psi_{\mathrm{I}}-\Psi_{\mathrm{II}}=\frac{\mathrm{RT}}{\mathrm{F}}\left(t_{+} \ln \frac{a_{\mathrm{II}}}{a_{\mathrm{I}}}+t_{-} \ln \frac{a_{\mathrm{II}}}{a_{\mathrm{I}}}+t_{\mathrm{W}} \ln \frac{a_{\mathrm{WII}}}{a_{\mathrm{WI}}}\right)
$$

in which $t_{+}, t_{-}$, and $t_{\mathrm{w}}$ are the transference number of cation, anion, and water, respectively, and $a_{\mathrm{I}}$ and $a_{\mathrm{II}}$ the mean activities of electrolytes in solution I and II, and $a_{\mathrm{wI}}$ and $a_{\mathrm{wII}}$ the activities of water in solution I and II. From equation (1) the transport number $T_{i}$ for an ion $i\left(T_{i}=z_{i} t_{i}\right.$, where $z_{i}$ is the valence of $i$ ) can be estimated, if the last term of the equation is evaluated or is so small as to be negligible.

The biionic potential is defined as the membrane potential across a membrane which separates two electrolyte solutions with different counterions, i.e., different mobile ions carring the charge opposite to the fixed charge on the membrane. For an anion exchange membrane separating solutions I and II each containing an univalent anion $\mathrm{X}^{-}$or $\mathrm{Y}^{-}$, respectively, the main terms of the 
biionic potential can be give by,

$$
\Psi_{\mathrm{I}}-\Psi_{\mathrm{II}}=-\frac{\mathrm{RT}}{\mathrm{F}}\left(\ln \frac{a_{y}}{a_{x}}+\ln \frac{\bar{v}_{y} \bar{\gamma}_{x}}{\bar{v}_{a} \bar{\gamma}_{y}}\right)
$$

in which $\bar{v}_{x}, \bar{v}_{y}$ and $\bar{\gamma}_{x}, \bar{\gamma}_{y}$ are the mobilities and the activity coefficients of each anion in the membrane. It is well known that the biionic potential is a measure of the selectivity of a membrane for different anions, because the transport ratio, $t_{y} / t_{x}$ is given as follow,

$$
\frac{t_{y}}{t_{x}}=\frac{\bar{v}_{y} \bar{c}_{y}}{\bar{v}_{x} \bar{c}_{x}}=\frac{\bar{v}_{y} \bar{\gamma}_{x} \bar{a}_{y}}{\bar{v}_{x} \bar{\gamma}_{y} \bar{a}_{x}}
$$

in which $\bar{c}_{x}, \bar{c}_{y}$, and $\bar{a}_{x}, \bar{a}_{y}$ are the concentrations and the activities in the membrane, respectively. By the biionic potential arised between solutions of the same activity, the transport ratio is expressed as follow,

$$
\frac{t_{y}}{t_{x}}=\exp \left\{-\frac{\mathrm{F}}{\mathrm{RT}}\left(\Psi_{\mathrm{I}}-\Psi_{\mathrm{II}}\right)\right\}
$$

provided that the Donnan equilibrium, $\bar{a}_{y} / \bar{a}_{x}=$ $a_{y} / a_{x}$ is established.

The fixed charge concentration on an ion exchange membrane is one of the important properties characterizing the membrane. According to the fixed charge theory of membrane potential proposed by Teorel1 ${ }^{11}$ and by Meyer and Sievers ${ }^{12}$, the membrane potential across an anion exchange membrane is given by the equation,

$$
\begin{array}{r}
\Delta \Psi=\frac{\mathrm{RT}}{\mathrm{F}}\left\{\ln \frac{C_{1} \sqrt{4 C_{2}^{2}+X^{2}}+X}{C_{2} \sqrt{4 C_{1}^{2}+X^{2}}+X}\right. \\
\left.-\bar{U} \ln \frac{\sqrt{4 C_{1}^{2}+X^{2}}-X \tilde{u}}{\sqrt{4 C_{2}^{2}+X^{2}}-X \bar{u}}\right\}
\end{array}
$$

where $\bar{U}=(\bar{u}-\bar{v}) /(\bar{u}+\bar{v})$ with $\bar{u}$ and $\bar{v}$ being the mobilities of the cation and the anion in the membrane, and $X$ is the charge fixed on the membrane expressed in equivalents/liter. Since equation (5) enables the theoretical membrane potential to be calculated as function of $C_{2}$ for different mobility ratio $(\bar{u} / \bar{v})$ at a fixed charge concentration and a fixed concentration ratio $\left(C_{1} / C_{2}\right)$, the fixed charge concentration on the membrane can be evaluated, using the best-fit approach to the membrane potentials obtained experimentally by varying $C_{2}$.

\section{Experimental}

Nickel hydroxide precipitate membranes were prepared on a cellulose sheet by allowing $\mathrm{Ni}\left(\mathrm{NO}_{3}\right)_{2}$ and an alkaline solution to diffuse from the two sides through the sheet under three different pre- cipitation conditions, using (1) $0.05 \mathrm{M} \mathrm{Ni}\left(\mathrm{NO}_{3}\right)_{2}$ and $0.1 \mathrm{M} \mathrm{NaOH}$, (2) $0.05 \mathrm{M} \mathrm{Ni}\left(\mathrm{NO}_{3}\right)_{2}$ and $0.1 \mathrm{M}$ $\mathrm{NH}_{4} \mathrm{OH}$, and (3) $0.5 \mathrm{M} \mathrm{Ni}\left(\mathrm{NO}_{3}\right)_{2}$ and $0.5 \mathrm{M}$ $\mathrm{Na}_{2} \mathrm{CO}_{3}$. The cellulose sheet used was made from a tube for dialysis and, prior to precipitation, was boiled with redistilled water in order to remove the impurities. The precipitate formed on the surface of the cellulose sheet contacting to the $\mathrm{Ni}\left(\mathrm{NO}_{3}\right)_{2}$ solution was $\mathrm{Ni}(\mathrm{OH})_{2}$ for solutions (1) and (2), and basic $\mathrm{NiCO}_{3}$ for solutions (3). The precipitate was also prepared on the other side of the surface of the sheet by interchanging the two solutions. The surface area of the membranes was $0.5 \mathrm{~cm}^{2}$, and the membrane thickness was about $0.5 \mathrm{~mm}$ for $\mathrm{Ni}(\mathrm{OH})_{2}$ and $0.1 \mathrm{~mm}$ for basic $\mathrm{NiCO}_{3}$. The membranes were washed with redistilled water for more than 2 days to remove free electrolytes from them.

In addition to the precipitate membranes on the cellulose sheet, a pressed $\mathrm{Ni}(\mathrm{OH})_{2}$ precipitate membrane was also prepared at $10 \mathrm{~kg} \cdot \mathrm{cm}^{-2}$ from precipitate powders produced by mixing $0.05 \mathrm{M}$ $\mathrm{Ni}\left(\mathrm{NO}_{3}\right)_{2}$ with $0.1 \mathrm{M} \mathrm{NH}_{4} \mathrm{OH}$.

The membrane potentials were measured in an electrochemical cell, $\mathrm{Hg}-\mathrm{Hg}_{2} \mathrm{Cl}_{2}$ / saturated $\mathrm{KCl}$ Agar / solution I / membrane / solution II / saturated $\mathrm{KCl}$-Agar $/ \mathrm{Hg}-\mathrm{Hg}_{2} \mathrm{Cl}_{2}$, shown in Fig. 1 . In each half cell, a teflon tube to flow the electrolyte solution from a vessel and a Luggin capillary connected to a saturated callomel electrode were fixed. The whole cell was kept in a shield box.



Fig. 1. The cell for membrane potential measurements:

1. Nickel hydroxide membrane, 2. Cellulose sheet, 3. Luggin capillaries, 4. Vessels of electrolyte solution. 
made with iron plates and copper networks to reduce electrical noise in potential measurements. The potentials were measured with a type TR$84 \mathrm{~m}$ potentiometer of Rigaku Denki Co., Ltd. The various electrolyte solutions were prepared from GR-grade Chemicals by use of redistilled water. The temperature of solutions in the cell and the vessel was controlled to $25^{\circ} \pm 0.1^{\circ} \mathrm{C}$ with circulating water.

\section{Results}

The potential difference across a membrane is generally known to decrease with the increased diffusion of neutral electrolytes and water due to the concentration difference between the solutions separated by the membrane, because the actural concentration difference of two interfacial solutions becomes smaller than that of bulk solutions as the diffusion increases. This decrease of potential difference may be significant in the system of a membrane of high porosity, such as precipitate membranes. In measurements of the membrane potentials across the nickel hydroxide precipitate membranes, therefore, the electrolyte solutions were allowed to flow stationally to the membrane interface, in order to minimize the potential difference decrease. Figure 2 shows the dependence of membrane potentials on the flow rates of elec-



Fig. 2. Variations of membrane potential with flow rate of $\mathrm{NaCl}$ solution. The membrane prepared with $0.1 \mathrm{M} \mathrm{NaOH}$ and $0.05 \mathrm{M} \mathrm{Ni}\left(\mathrm{NO}_{3}\right)_{2}$ on the cellulose sheet was used. trolyte solution, in which the membrane prepared with $\mathrm{Ni}\left(\mathrm{NO}_{3}\right)_{2}$ and $\mathrm{NaOH}$ on the cellulose sheet is used and the membrane potential $\left(\Psi_{0.01}-\Psi_{x}\right)$ is measured referring to the standard solution of $1 \times 10^{-2} \mathrm{M} \mathrm{NaCl}$. At the flow rates larger than $10 \mathrm{ml} \cdot \mathrm{min}^{-1}$, the membrane potentials are seen to be almost constant. After the flow was cut, the potential differences decreased gradually. The membrane potentials at zero flow rate shown in Fig. 2 are the values at 2 minutes after the flow is stopped. In the systems of $1 \times 10^{-4} \mathrm{M}$ and $1 \times 10^{-1}$ $\mathrm{M} \mathrm{NaCl}$, the membrane potential is significantly influenced with the flow rate. In the former case, since the solution is rather dilute, even a small $\mathrm{NaCl}$ diffusion from $10^{-2} \mathrm{M} \mathrm{NaCl}$ to $10^{-4} \mathrm{M}$ $\mathrm{NaCl}$ solution gives rise to a great effect on the potential difference. In the later case where the concentration difference is relatively large, a large $\mathrm{NaCl}$ and water diffusion decrease the potential difference.

Figure 3 shows the relationship between the membrane potential in the system of neutral electrolytes of sodium salt and the mean activity ratio referred to the standard concentration of $1 \times 10^{-2} \mathrm{M}$, in which the membrane used is prepared with $\mathrm{Ni}\left(\mathrm{NO}_{3}\right)_{2}$ and $\mathrm{NaOH}$. The negative slope of lines means that the nickel hydroxide



Fig. 3. Variations of membrane potential with mean activity ratio referred to $0.01 \mathrm{M}$ solution across the membrane prepared with $0.1 \mathrm{M} \mathrm{NaOH}$ and $0.05 \mathrm{M} \mathrm{Ni}\left(\mathrm{NO}_{3}\right)_{2}$. The electrolytes used were: (O) $\mathrm{NaCl}$; $(\square) \mathrm{NaNO}_{3} ;(\triangle) \mathrm{NaClO}_{4}$; and (•) $\mathrm{Na}_{2} \mathrm{SO}_{4}$. 
precipitate membrane is an anion exchange membrane. The membrane potentials are almost the same in chloride, nitrate, and perchlorate solutions. In sulphate solution system, the membrane potential is a half value of the univalent anion systems. The apparent transport numbers of anions calculated in linear parts are 0.98 for all anions, in which the transference of water is omitted.

Figure 4 shows the membrane potentials in $\mathrm{NaCl}$ solutions across the nickel hydroxide precipitate membranes prepared under various conditions, in which the mean activity ratio is also referred to $1 \times 10^{-2} \mathrm{M} \mathrm{NaCl}$ standard solution. Except for the pressed membrane, the membrane potentials are almost the same for all the membranes used, so that the characteristics as an anion exchange membrane is the same for three types of precipitate membranes on the cellulose sheet. Especially, through the membraned prepared with $\mathrm{Ni}\left(\mathrm{NO}_{3}\right)_{2}$ and $\mathrm{Na}_{2} \mathrm{CO}_{3}$ where the composition of the precipitate is idealy $\mathrm{NiCO}_{3}$. $2 \mathrm{Ni}(\mathrm{OH})_{2}$ but is not determined here, any changes in the ion selectivity are not observed in the presense of carbonate ions in the membrane. The membrane potentials across the pressed $\mathrm{Ni}(\mathrm{OH})_{2}$

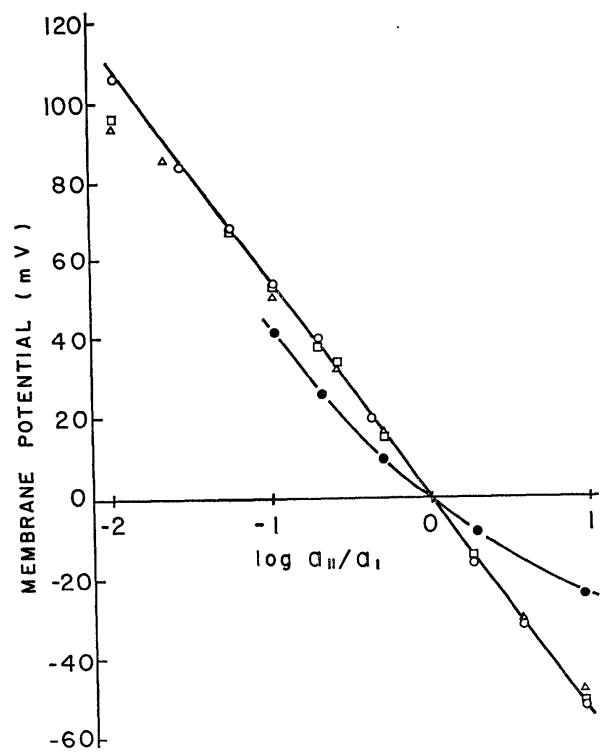

Fig. 4. Membrane potentials across the nickel hydroxide membranes prepared in various conditions in $\mathrm{NaCl}$ solution. The membranes used were prepared with: (O) $0.1 \mathrm{M} \mathrm{NaOH}$ and $0.05 \mathrm{M} \mathrm{Ni}\left(\mathrm{NO}_{3}\right)_{2} ;(\square)$ $0.1 \mathrm{M} \mathrm{NH} \mathrm{NH}_{4} \mathrm{OH}$ and $0.05 \mathrm{M} \mathrm{Ni}\left(\mathrm{NO}_{3}\right)_{2}$;

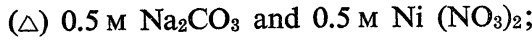
and $\left(\bullet\right.$ pressed $\mathrm{Ni}(\mathrm{OH})_{2}$. membrane, however, are small compared to the others. Furthermore, in the system of $1 \times 10^{-2}$ $1 \times 10^{-3} \mathrm{M} \mathrm{NaCl}$ solutions, the membrane potential for the pressed $\mathrm{Ni}(\mathrm{OH})_{2}$ was reduced from $40 \mathrm{mV}$ to $38 \mathrm{mV}$ and to $36 \mathrm{mV}$ at 1 and 10 minutes after the stop of electrolyte flow, respectively. These behaviours of the pressed $\mathrm{Ni}(\mathrm{OH})_{2}$ membrane is probably attributed to the large salt flow due to the high porosity.

The biionic potentials across the nickel hydroxide precipitate membrane separating two electrolyte solutions containing different counterions were measured for the membrane prepared with $\mathrm{Ni}\left(\mathrm{NO}_{3}\right)_{2}$ and $\mathrm{NaOH}$. In the systems prepared by using $\mathrm{NaCl}, \mathrm{NaNO}_{3}$, and $\mathrm{NaClO}_{4}$, the biionic potentials were measured by keeping the concentration of $\mathrm{NaX}$ constant at $1 \times 10^{-2} \mathrm{M}$ and by varying the molarity of $\mathrm{NaY}$ from $1 \times 10^{-4}$ to $1 \times 10^{-1} \mathrm{M}$, and again by keeping $\mathrm{NaY}$ constant at $1 \times 10^{-2} \mathrm{M}$ and varying $\mathrm{NaX}$ from $1 \times 10^{-4}$ to $1 \times 10^{-1} \mathrm{M}$. These measurements were extended to the three systems. Figure 5 shows the biionic potentials for the two sets of $\mathrm{NaCl}-\mathrm{NaNO}_{3}$ system, the logarithm of the mean activity ratio $a_{\mathrm{NaNO}_{3}} /$ $a_{\mathrm{NaCl}}$ is used as abscissa. In the same way, Figs. 6 and 7 show the biionic potentials for the sets of

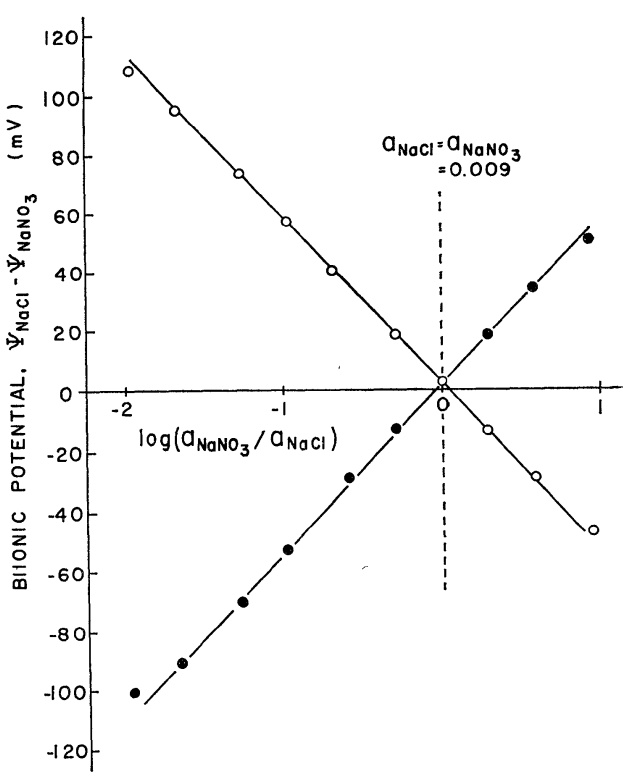

Fig. 5. Biionic potentials across the nickel hydroxide membrane prepared with $0.1 \mathrm{M}$ $\mathrm{NaOH}$ and $0.05 \mathrm{M} \mathrm{Ni}\left(\mathrm{NO}_{3}\right)_{2}$ for $\mathrm{NaCl}-$ membrane- $\mathrm{NaNO}_{3}$ system, in which the concentrations of $\mathrm{NaCl}(\mathrm{O})$ and $\mathrm{NaNO}_{3}$ (•) were kept constant at $1 \times 10^{-2} \mathrm{M}$, respectively. 




Fig. 6. Biionic potentials across the nickel hydroxide membrane for $\mathrm{NaCl}$-membrane$\mathrm{NaClO}_{4}$ system, in which concentrations of $\mathrm{NaCl}(\square)$ and $\mathrm{NaClO}_{4}$ (四) were kept to constant at $1 \times 10^{-2} \mathrm{M}$, respectively.

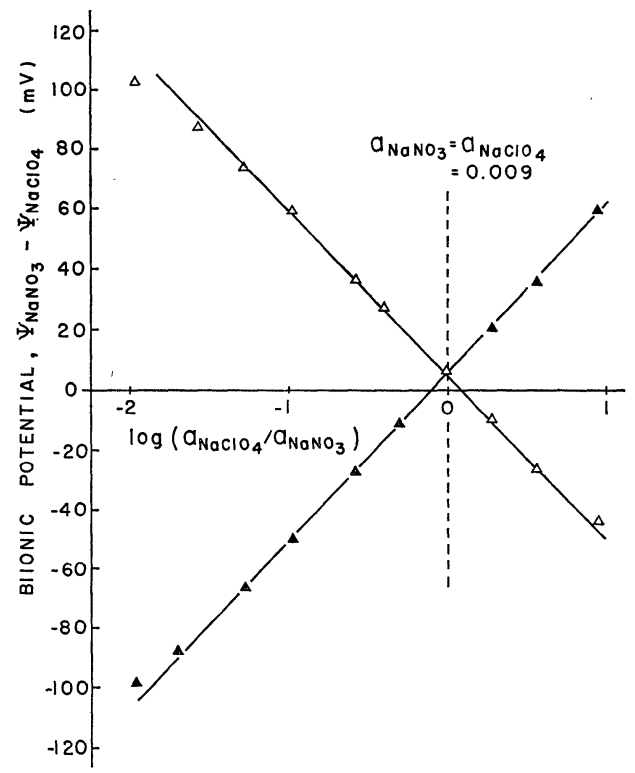

Fig. 7. Biionic potentials across the nickel hydroxide membrane for $\mathrm{NaNO}_{3}$-membrane- $\mathrm{NaClO}_{4}$ system, the concentrations of $\mathrm{NaNO}_{3}(\Delta)$ and $\mathrm{NaClO}_{4}(\Delta)$ were kept in which constant at $1 \times 10^{-2} \mathrm{M}$, respectively.

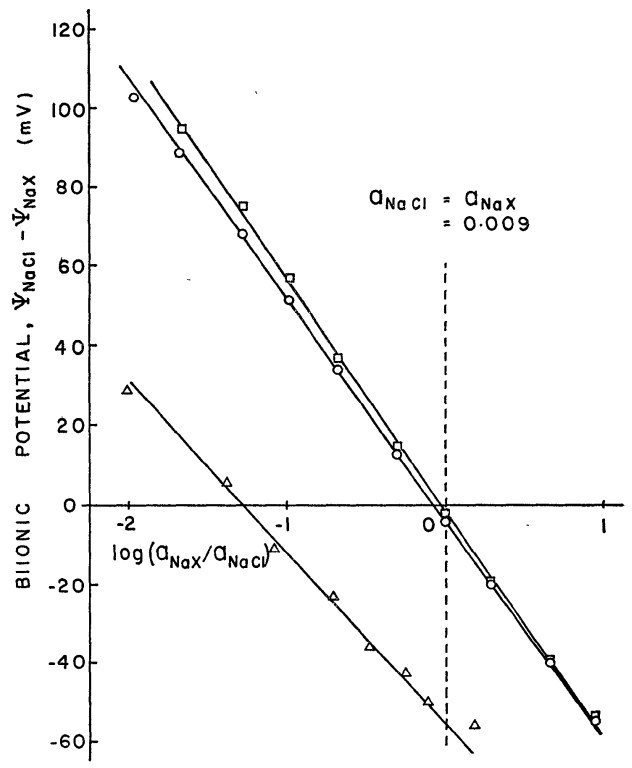

Fig. 8. Biionic potentials across the nickel hydroxide membrane for $1 \times 10^{-2} \mathrm{M} \mathrm{NaCl}-$ membrane- $\mathrm{NaBr}(\mathrm{O}), \mathrm{NaI}(\square)$, and $\mathrm{NaOH}$ $(\triangle)$ systems.

$\mathrm{NaCl}-\mathrm{NaClO}_{4}$ and $\mathrm{NaNO}_{3}-\mathrm{NaClO}_{4}$ systems, respectively. Good straight-line relations are seen for all sets of the biionic systems. Since the potential of intersection of the two straight-lines with the vertical line at the same activity, i.e., $a_{y} / a_{x}=1$, are almost the same for each two sets of the systems, the transport ratio is calculated by using equation (4). The transport ratio thus obtained are $t_{\mathrm{NO}_{3}} / t_{\mathrm{C} 1}=0.91 \pm 0.01, t_{\mathrm{C} 1 \mathrm{O}^{4}} / t_{\mathrm{C} 1}=0.70 \pm$ 0.02 , and $t_{\mathrm{ClO}_{4}} / t_{\mathrm{NO}_{3}}=0.80 \pm 0.01$. Similarly, Fig. 8 shows the biionic potentials arising across the membrane separating the standard solution of $1 \times$ $10^{-2} \mathrm{M} \mathrm{NaCl}$ and $\mathrm{NaBr}, \mathrm{NaI}$, and $\mathrm{NaOH}$. The transport ratios calculated for the combination of $\mathrm{Cl}^{-}$and $\mathrm{Br}^{-}, \mathrm{I}^{-}$, and $\mathrm{OH}^{-}$are 1.2, 1.1, and 8.6, respectively. From the transport ratios referred to $\mathrm{Cl}^{-}$ions, the order of the selectivity of anions transporting through the membrane is obtained as follow,

$$
\mathrm{OH}^{-}>\mathrm{Br}^{-}>\mathrm{I}^{-}>\mathrm{Cl}^{-}>\mathrm{NO}_{3}^{-}>\mathrm{ClO}_{4}^{-}
$$

According to the fixed charge theory, the membrane potential is given by equation (5) which contains two Donnan potentials at the two solution-membrane interfaces and a diffusion potential arising from the unequal concentrations of the counterions at the two membrane faces. Fig. 9 shows the membrane potential theoretically 




Fig. 9. Theoretical membrane potentials for an anion exchange membrane in uni-univalent electrolyte at constant solution concentration ratio $\left(C_{1} / C_{2}=10\right)$ as a function of $-\log C_{2}$.

calculated for an anion exchange membrane as a function of $C_{2}$ for different fixed charge concentrations $(X)$ and different mobility ratios $(\bar{u} / \bar{v})$ where calculation is made for uni-univalent electrolyte and constant concentration ratio $C_{1} / C_{2}=$ 10. Since the theoretical curves of $X=1$ for each $\bar{u} / \bar{v}$ value are shifted horizontally by $\log X$ for different values of $X$, the shift of an experimental curve to a coinciding theoretical curve of $X=1$ gives $\log X$ and $\bar{u} / \bar{v}$ for the membrane. In Fig. 10 , the measured membrane potential across the membrane prepared with $\mathrm{Ni}\left(\mathrm{NO}_{3}\right)_{2}$ and $\mathrm{NaOH}$ on the cellulose sheet is plotted in $\mathrm{NaCl}$ and $\mathrm{KCl}$ solutions. No significant differences between the two electrolytes are observed. The solid line in Fig. 10 is the theoretical curve assuming $X=$ $0.4 \mathrm{~N}$ and $\bar{u} / \bar{v}=0.65$. In these cases, the agreement between the experimental and theoretical curves is not so good. However, with this method, the fixed ion concentration and the mobility ratio were estimated obtained to be $X=0.4 \mathrm{~N}$ and $\bar{u} / \bar{v}=0.65$ for the nickel hydroxide precipitate membrane.

\section{Discussion}

By using X-ray powder diffraction method, the weak diffraction lines of $\beta-\mathrm{Ni}(\mathrm{OH})_{2}$ were obtained for the nickel hydroxide precipitates dried at $110^{\circ} \mathrm{C}$ after separation from the cellulose

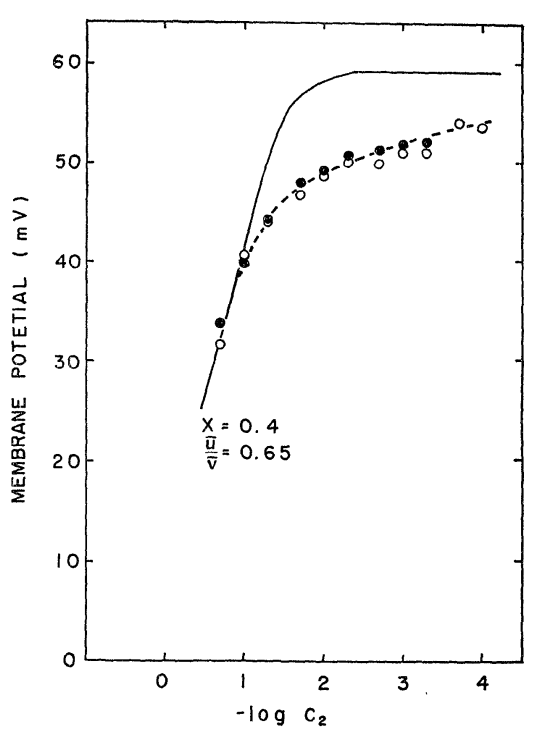

Fig. 10. Experimental membrane potentials as a function of $-\log C_{2}$ across the nickel hydroxide precipitate membrane prepared with $0.1 \mathrm{M} \mathrm{NaOH}$ and $0.05 \mathrm{M} \mathrm{Ni}$ $\left(\mathrm{NO}_{3}\right)_{2}$. The electrolyte used were: (O) $\mathrm{NaCl}$; and (0) $\mathrm{KCl}$. The solid line is the theoretical curve of $X=0.4 \mathrm{~N}$ and $\bar{u} / \bar{v}=0.65$.

sheet. Thus the precipitation membranes are regarded as aggregation films constracted by a poor crystallized $\beta-\mathrm{Ni}(\mathrm{OH})_{2}$ of which the structure and the reactivity have been reported. ${ }^{13)}$ From the membrane potentials shown in Figs. 3 and 4 , the fixed charge characterizing the membranes as anion exchangers must be positive, that is, nickel cations on the surface of the particles constracting the membranes. Then, the $\mathrm{OH}^{-}$ ion combined with the nickel cations on the surface can act as one of counterions. It appears, therefore, that in the membrane there are ion transfer passages inside which the wall is covered with the $\mathrm{OH}^{-}$ions. As already proposed in previous paper, ${ }^{91}$ anions can be carried by the replacement of these $\mathrm{OH}^{-}$ions, if electrical current flows through the membranes.

As is indicated in equation (1), the transference numbers of ions through the membrane must be calculated from the membrane potential which contains the term of transference number of water. This term in differential form is represented by using the Gibbs-Duhem equation as follow,

$$
t_{\mathrm{w}} d \ln a_{\mathrm{w}}=-0.018 \mathrm{M} t_{\mathrm{w}} d \ln {a_{ \pm}}^{2}
$$

where $\mathrm{M}$ and $a_{ \pm}$are the molality and the mean 
activity of the electrolyte in the solution. Since the transference number of water was about 5 to 7 for anions investigated, ${ }^{14)}$ and since the molality of the electrolyte used is small, the contribution of the transference of water to the total membrane potentials is negligible small. From the calculated transport number of anions, 0.98 , it is evident that the nickel hydroxide precipitate membranes indicates a high selectivity for anions.

The transport ratio referred to $\mathrm{Cl}^{-}$ions is calculated from the results shown in Figs. 5 through 8 by using equation (4). Furthermore, from measurements of radio-tracer Cl-36 transport through the membrane in the mixed solutions of $\mathrm{NaCl}-\mathrm{Na}_{2} \mathrm{SO}_{4}$ and $\mathrm{NaCl}-\mathrm{NaOH}$, it was established that the selectivity of $\mathrm{SO}_{4}{ }^{2-}$ ions was much higher than $\mathrm{Cl}^{-}$ions and lower than $\mathrm{OH}^{-}$ ions. ${ }^{9)}$ The selectivity among anions containing $\mathrm{SO}_{4}{ }^{2-}$ ions is, therefore, as follow,

$$
\mathrm{OH}^{-}>\mathrm{SO}_{4}{ }^{2-}>\mathrm{Br}^{-}>\mathrm{I}^{-}>\mathrm{Cl}^{-}>\mathrm{NO}_{3}{ }^{-}>\mathrm{ClO}_{4}{ }^{-}
$$

The above order of the selectivity is the same as that of the mobility of each anion in aqueous solution.

In application of equation (4) to the biionic potentials a membrane-controlled system is assumed, that is, the biionic potential is composed of two Donnan potentials and one diffusion potential across the membrane. For the case of film-diffusion-controlled biionic system, that is, the biionic potential is composed of two Donnan potentials and two interdiffusion potentials produced in two membrane solution interphase layers or films, the biionic potential is given by,

$$
\Psi_{\mathrm{I}}-\Psi_{\mathrm{II}}=-\frac{\mathrm{RT}}{\mathrm{F}}\left(\frac{C_{x}}{C_{y}}\right)\left(\frac{D_{y}}{D_{x}}\right)
$$

where $C_{x}$ and $C_{y}$ are the bulk concentrations, and $D_{x}$ and $D_{y}$ and the diffusion constants of anions in the films. The difference in the transport ratio of anions obtained in the membrane system is, however, greater than the ratio expected from the mobility of anions in aqueous solution. This may indicate that the nickel hydroxide precipitate membranes can be regarded as a membrane-controlled biionic system.

In various methods as appeared in literature to estimate the fixed ion concentration, the titration method is simple and has often been used but only for well characterized ion exchange membranes. ${ }^{15}$ This method is, however, disadvantageous in that it measured not only the fixed charge concentration at the wall of passages but also inside the membrane. For precipitate membranes, therefore, many authors ${ }^{16,17)}$ proposed to use the potentiometric method according to the fixed charge theory. Although agreement between the theoretical and the experimental curves is not so good as is shown in Fig. 10, the fixed ion concentration on the nickel hydroxide membrane is estimated to about $0.4 \mathrm{~g}$ equiv./liter. It is obvious from equation (5), that this potentiometric method can be rigorously applied only if the concentration of electrolyte used is small, i.e., the fixed ion concentration is small, because equation (5) used the concentration in place of the activity. In addition to uncertainity of the fixed ion concentration at high concentrations, significant influences of transference of water and diffusion of electrolyte on the membrane potential is expected to occur in concentrated solution. In spite of these uncertainities for the fixed ion concentration, it is evident that the concentration of anions can be increased more than $0.1 \mathrm{~g}$ equiv./liter in the passages through the nickel hydroxide membranes.

\section{Conclusions}

From measurements of the membrane potential of nickel hydroxide precipitate membranes, the following conclusions are drawn on the characteristics of the membranes:

1. The membrane shows a high selectivity for anions, i.e., the transport number of anions through the membrane is 0.98 .

2. The order of selectivity for anions is $\mathrm{OH}^{-}>$ $\mathrm{SO}_{4}{ }^{2+}>\mathrm{Br}^{-}>\mathrm{I}^{-}>\mathrm{Cl}^{-}>\mathrm{NO}_{3}{ }^{-}>\mathrm{ClO}_{4}{ }^{-}$.

3. The concentration of the fixed charge on the membrane is about $0.4 \mathrm{~g}$ equiv./liter.

Acknowledgement One of the authors (M. S.) thanks the Sakkokai Foundations for a scholarship.

(Received October 28, 1974)

\section{References}

1) H. Freundlich: Z. Phys. Chem., 44, 151 (1903).

2) S. Gnosh \& N. R. Dhar: Kolloid-Z., 44, 149 (1928).

3) M. Abe \& T. Ito: Nippon Kagaku Zasshi, 86, 817 (1965).

4) L. Blok \& P. L. de Bruyn: J. Colloid Interface Sci., 32, 533 (1970).

5) F. Lohmann: Kolloid-Z u.Z. Polymere, 250, 748 (1972).

6) P. Ruetschi: J. Electrochem. Soc., 120, 331 (1973). 
7) I. Suzuki, N. Masuko \& Y. Hisamatsu: Corr. Eng. (Boshoku Gijutsu), 20, 319 (1971).

8) T. Ito: Nippon Kagaku Kaishi, 1213 (1974).

9) M.LSakashita \& N. Sato: Electrochim. Acta, to be published.

10) G. Scatchard: J. Am. Chem. Soc., 75, 2883 (1953).

11) T. Teorell: Proc. Soc. exp. Biol. Med., 33, 192 (1935).

12) K. H. Meyer \& J. F. Sievers: Helv. Chim. Acta, 19, 649, 665, 987 (1936).
13) M. Sakashita \& N. Sato: Bull. Chem. Soc. Japan, 46, 1983 (1973).

14) M. Sakashita \& N. Sato: J. Electroanal. Chem., in printing.

15) K. Sollner \& J. Anderman: J. Gen. Physiol., 27, 433 (1944).

16) N. Lakshminarayanaiah: Chem. Rev., 65, 491 (1965).

17) I. Altug \& M. L. Hair: J. Phys. Chem., 72, 599 (1968). 